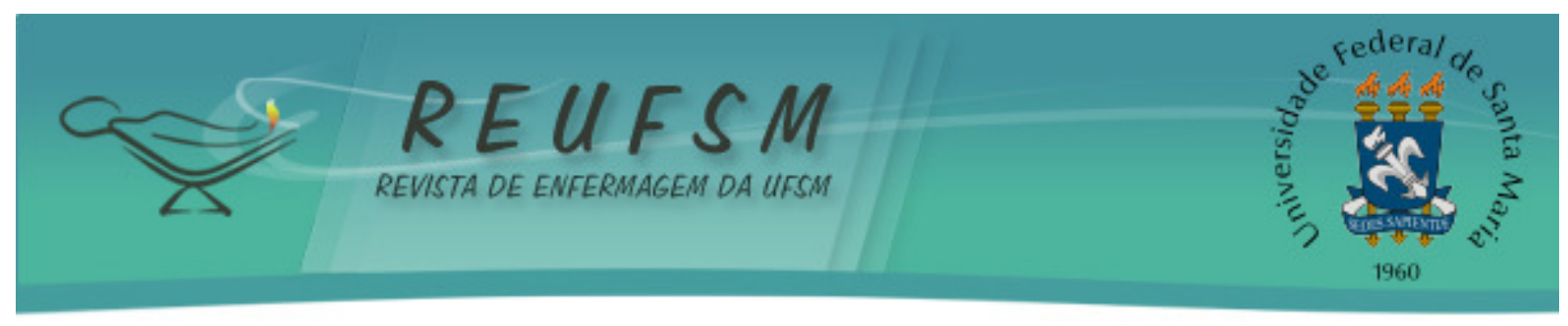

ARTIGO ORIGINAL

\title{
A INFLUÊNCIA DO TOQUE NO CUIDADO ÀS CRIANÇAS ESPECIAIS
}

THE INFLUENCE OF TOUCH IN CARING FOR SPECIAL CHILDREN

\section{LA INFLUENCIA DEL TACTO EN EL CUIDADO A LOS NIÑOS CON NECESIDADES ESPECIALES}

\author{
Magali Zilá Vitória Soares ${ }^{1}$ \\ Julia Vargas de Oliveira Vargas Bitencourt ${ }^{2}$ \\ Alexander Garcia Parker ${ }^{3}$ \\ Ana Maria Fernandes Borges ${ }^{4}$ \\ Mara Ambrosina de Oliveira Vargas ${ }^{5}$ \\ Soraia Dornelles Schoeller ${ }^{6}$
}

Doi: $10.5902 / 2179769210036$

RESUMO: Objetivo: identificar a influência de toque no cuidado às crianças com necessidades especiais na percepção dos trabalhadores. Método: pesquisa qualitativa em que fizeram parte da investigação oito profissionais de um Centro de Integração à Criança Especial do Município de Porto Alegre, Rio Grande do Sul. Para interpretação dos dados, utilizou-se a análise de conteúdo. Resultados: originaram-se as categorias percepção dos cuidadores em relação à influência do toque como instrumento de comunicação entre a criança especial e o profissional; percepção dos cuidadores em relação à influência do toque no bem-estar da criança especial e percepção dos cuidadores em relação à influência do toque na reabilitação da criança especial. Conclusões: os resultados evidenciaram que o toque é uma ferramenta que influencia no bem-estar das crianças e caracteriza-se por ser um instrumento de comunicação alternativa e, modo de aproximação entre o profissional e a criança, possibilitando a criação de um vínculo positivo e consequentemente, favorecendo o processo de reabilitação.

Descritores: Crianças com deficiência; Cuidado da criança; Pessoal de saúde.

ABSTRACT: Aim: to identify the influence of touching in the process of caring for children with special needs in the perception health professionals. Method: the sample consisted of eight professionals of the Integration Center for Children with Special Needs in Porto Alegre, Rio Grande do Sul. Results: the content analysis arose the following categories: perceptions of caregivers with regards the influence of touch as a communication tool between the special child and the professional; the perception of the caregivers regarding the influence of touch on the welfare of the child and the perception of the caregiver regarding the influence of touch on the rehabilitation of the special child. Conclusions:

\footnotetext{
${ }^{1}$ Cursando Especialização em Enfermagem em Emergência, no Centro Educacional São Camilo do Sul. Enfermeira graduada pelo Centro Universitário Metodista do Sul. Enfermeira na empresa Vip Home Care. Email: megvit@hotmail.com

${ }^{2}$ Mestre em enfermagem pela UFRJ: Escola Anna Nery. Professora do Curso de Graduação em Enfermagem Universidade Federal Fronteira Sul - UFFS. E-mail: ivanorbitencourt@gmail.com

${ }^{3}$ Mestre em Enfermagem. Professor da Universidade Federal Fronteira Sul. E-mail: alexander.parker@uffs.edu.br

${ }^{4}$ Mestre em Enfermagem pelo Programa de Pós Graduação em Enfermagem da Universidade Federal de Santa Catarina. Membro do Grupo de Pesquisa PRÁXIS. E-mail: am.borgesmarques@gmail.com

${ }^{5}$ Doutora em Filosofia em Enfermagem Universidade Federal de Santa Catarina (UFSC). Professora do Departamento e Programa de Pós-graduação em Enfermagem (UFSC). Pesquisadora e Vice-líder do Grupo de Pesquisa PRÁXIS/UFSC - trabalho, cidadania, saúde e Enfermagem. E-mail: maraav@terra.com.br

${ }^{6}$ Doutora em Enfermagem pela Universidade Federal de Santa Catarina (UFSC). Professora do Departamento de Enfermagem (UFSC). Pesquisadora do Grupo de Pesquisa PRÁXIS/UFSC - trabalho, cidadania, saúde e Enfermagem. E-mail: soraia@ccs.ufsc.br
} 


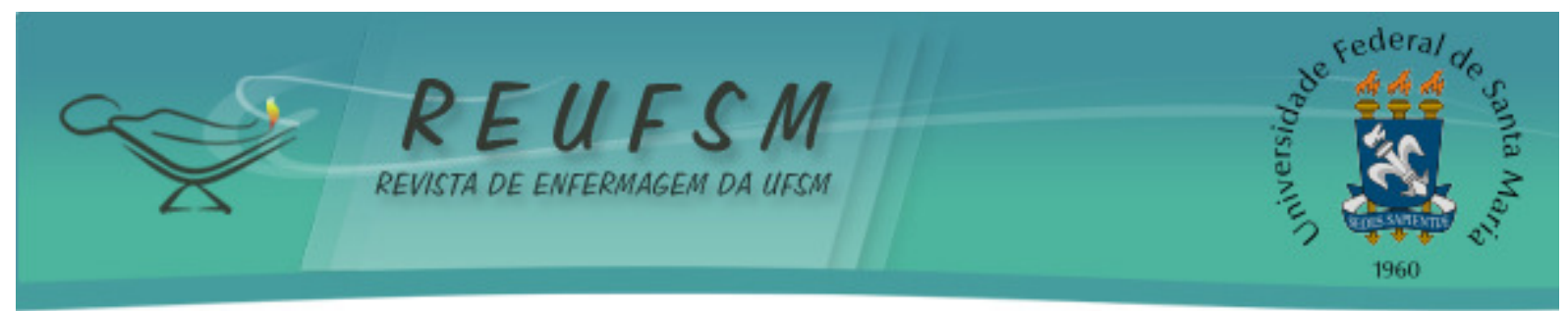

the results showed that touch is a tool that influences the well-being of children and is portrayed by being a communication tool that approach the professionals into the children, enabling the creation of a positive bond and favoring the rehabilitation.

Descriptors: Disabled children; Child care; Health personnel.

RESUMEN: Objetivo: identificar la influencia del tacto en el cuidado de niños en la percepción de los profesionales de la salud. Método: investigación cualitativa, realizada con ocho profesionales de un Centro de Integração à Criança Especial en Porto Alegre, RS. Para la interpretación de los datos fue utilizado el análisis de contenido. Resultados: percepción de cuidadores con relación a la influencia del tacto como instrumento de comunicación entre el niño especial y el profesional; percepción de los cuidadores con relación a la influencia del tacto en el bienestar del niño y la percepción de los cuidadores con relación a la influencia del tacto en la rehabilitación del niño. Conclusiones: fue evidenciado que el tacto es una herramienta que influencia en el bienestar de niños y se caracteriza por ser un instrumento de comunicación alternativa y de aproximación entre el profesional y el niño, creando un vínculo positivo y favoreciendo consecuentemente el proceso de rehabilitación.

Descriptores: Niños con discapacidad; Cuidado del niño; Personal de salud.

\section{INTRODUÇÃO}

Ao abordarmos o tema crianças com necessidades especiais, logo o relacionamos à deficiência. Toda e qualquer perda ou anormalidade, que afete a estrutura anatômica ou a função psicológica, fisiológica do organismo e que impeça o desempenho adequado de uma atividade específica considerada normal ao ser humano, é denominada deficiência. ${ }^{1} 0$ censo realizado no Brasil em 2010 mostra que cerca de 3,4 milhões de crianças $(0$ a 14 anos) possuem alguma deficiência, sendo as deficiências investigadas: visual, auditiva, motora, mental/intelectual e outras. ${ }^{2}$

0 cuidado às crianças com necessidades especiais muitas vezes fica reduzido apenas à atenção biomédica. Isso gera questionamentos acerca da importância do conceito ampliado de saúde a estas crianças, que apresentam outras carências além daquelas relacionadas, simplesmente, ao corpo biológico.

A pessoa que possui qualquer tipo de deficiência necessita de estratégias para melhorar a qualidade de vida. Contemporaneamente, o processo saúde doença encontra-se interligado à busca de uma maior qualidade de vida do ser humano, com a finalidade de se alcançar o bem-estar biopsicossocial e espiritual ${ }^{3}$, desvinculando-se de um olhar exclusivamente biológico da avaliação em saúde.

$\mathrm{Na}$ área da saúde, a comunicação é primordial para alcançar melhores resultados e desempenhos com a pessoa a ser cuidada e a equipe, podendo ser verbal ou não verbal. Uma série de gestos e expressões faciais e corporais completa a comunicação, tornando-a mais eficaz. ${ }^{4}$

Desde a década de 90 , o toque é considerado um meio de comunicação não verbal essencial durante toda a vida do ser humano, transmitindo afeto, segurança e proteção. Por outro lado, na doença o toque pode significar apoio, amparo e valorização da pessoa. ${ }^{5}$ Ele integra o cuidado e, por consequiência, é um instrumento de interação que pode promover bem-estar. Assim, o toque e o cuidado podem tornar-se inseparáveis diante das ações realizadas à pessoa a ser cuidada. ${ }^{6}$

Logo, no cenário de cuidados em saúde, as atitudes dos profissionais consistem em melhoria da qualidade de vida, contribuindo para a autonomia, amadurecimento e desenvolvimento das crianças com necessidades especiais. 0 foco da atenção não pode direcionar-se exclusivamente às suas limitações, percebendo-as, em uma perspectiva integral de saúde. Mesmo assim, é imprescindível ter o conhecimento das limitações que 


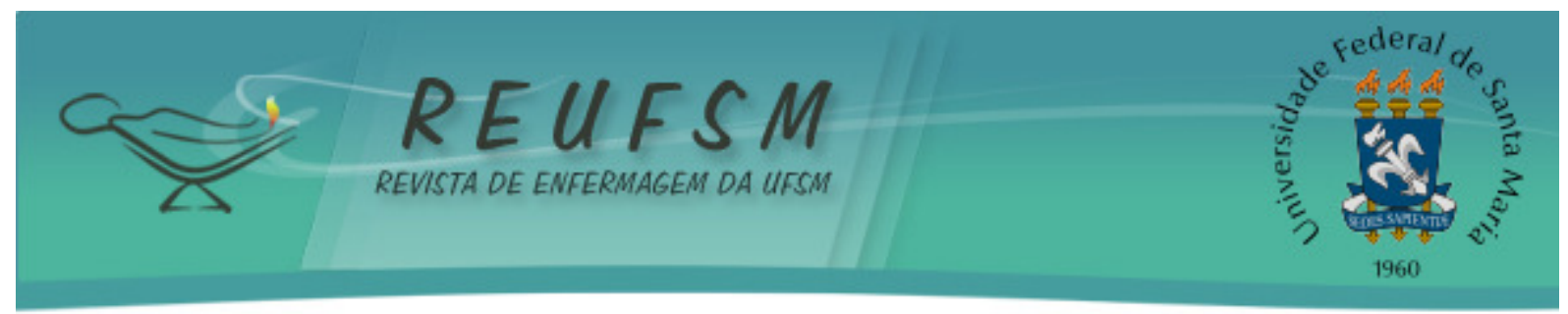

cada criança possui para o planejamento de um cuidado baseado nas necessidades de atenção, dedicação, carinho e respeito. ${ }^{3}$

A criança com necessidade especial não está isolada, pertence a um contexto familiar e social. Assim, o autocuidado deve ser estimulado e a família precisa participar. E este apoio é primordial para a reabilitação/habilitação da criança. A ação do cuidado é realizada de diversas formas que conduzem ao mesmo objetivo. ${ }^{7}$

Do ponto de vista fisiológico, utilizando-se como estratégia de cuidado o toque, a pele é o órgão de transformação de estímulos físicos em comunicadores químicos e em estados psicológicos ${ }^{8}$, sendo que qualquer experiência táctil ou de proximidade determina a sua representação em nível cerebral, enquanto experiência total, mútua e única. ${ }^{9}$ Portanto, o toque consiste na matriz de todos os sentidos, oferecendo determinado significado humano à pele, tratando-se de uma ação reveladora da dimensão da capacidade humana, assim como os estímulos que ali são provocados, os quais proporcionam a troca de energias entre o cuidador e a pessoa que recebe esse cuidado. ${ }^{10}$

0 toque pode despertar segurança, afeto e carinho, resultando em sensação de apoio e consequente relaxamento. As crianças, principalmente as com necessidades especiais, podem se tornar mais temerosas durante o cuidado, exatamente pela existência de limitações. Durante a reabilitação, os profissionais da saúde procuram minimizar esses sentimentos por meio de ações que proporcionam conforto e segurança. Assim, o toque se caracteriza como uma ferramenta que estabelece um maior vínculo entre o profissional de saúde e a criança, tornando o cuidado mais efetivo.

Nesta perspectiva, o presente estudo tem como questão norteadora: qual a percepção dos trabalhadores acerca da influência do toque no cuidado às crianças com necessidades especiais? Cujo objetivo é identificar a influência do toque no cuidado às crianças com necessidades especiais na percepção dos trabalhadores.

\section{MÉTODO}

Estudo de natureza qualitativa, do tipo exploratório e descritivo, sendo desenvolvido com oito profissionais de um Centro de Integração à Criança Especial, na capital do Rio Grande do Sul. Caracteriza-se por ser uma instituição que presta atendimento interdisciplinar a crianças e adolescentes portadores de deficiências múltiplas, por meio da educação, reabilitação e habilitação. Convém ressaltar que o cuidado é prestado a crianças com necessidades especiais que possuem deficiências múltiplas, como: Paralisia Cerebral; Lesão Medular; Síndromes Genéticas (West, Down); Malformações Congênitas; e outras patologias que resultam em problemas auditivos, visuais e de alimentação.

Como critérios de seleção, participaram profissionais da área da saúde, de ambos os sexos, que prestam atendimento à crianças com necessidades especiais e que desenvolvem suas atividades na referida instituição. Entre estes profissionais, havia pelo menos um representante das categorias descritas a seguir: terapeuta ocupacional, técnico de enfermagem, psicólogo e fisioterapeuta. Como critérios de exclusão: trabalhar no local num período menor que 1 ano. 0 período de coleta de dados ocorreu entre julho e agosto de 2011, após aprovação no Comitê de Ética do Centro Universitário Metodista do IPA, protocolo $n^{\circ} 59 / 2011$ e autorização da instituição em foco.

No transcurso do estudo os profissionais foram identificados por letras maiúsculas, sem possibilidades de reconhecimento da categoria profissional que emitia a opinião, visando preservar seus anonimatos. A coleta de dados ocorreu por meio de entrevista semiestruturada. 0 roteiro estabelecia questionamentos que visavam responder o objetivo da pesquisa. As entrevistas foram realizadas no local de trabalho dos participantes, em uma sala reservada que permitia a conversa sem interrupções. A coleta dos dados cessou 


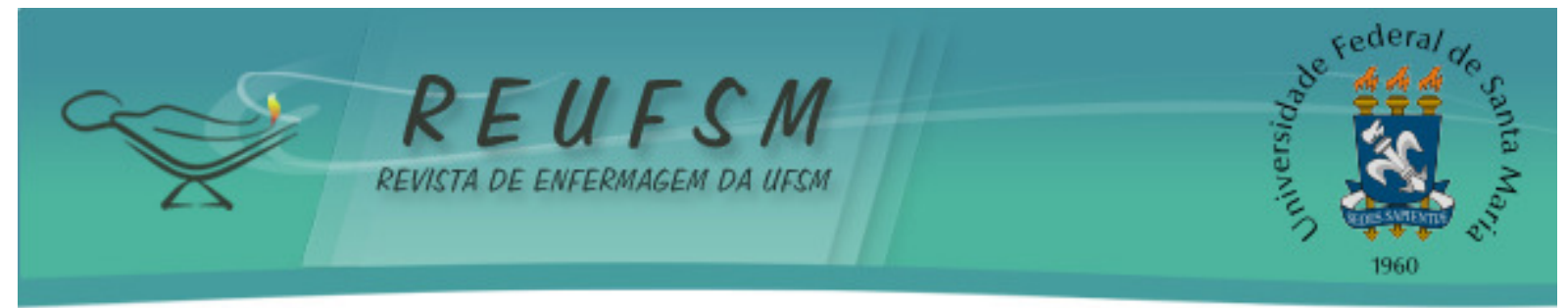

com a saturação dos dados. As entrevistas foram gravadas e transcritas para categorização e análise dos dados obtidos. Os participantes do estudo assinaram o Termo de Consentimento Livre e Esclarecido (TCLE).

Para a análise dos dados foi utilizada a análise de conteúdo temática, que consiste em descobrir os núcleos de sentido que compõem uma comunicação, cuja presença ou frequência signifiquem alguma coisa para o objeto analítico visado. ${ }^{11^{3}}$

\section{RESULTADOS}

Percepções dos cuidadores em relação à influência do toque: instrumento de comunicação entre a criança especial e o profissional toque:

Um dos entrevistados aponta o processo de interação ocorrido na vigência do

[...] o toque é uma via importantíssima de comunicação que auxilia na compreensão, é uma mensagem que a criança consegue perceber diretamente [...] que vai direto para o cérebro, eles conseguem de alguma forma decodificar [...]. (A)

Na sequência destaca-se o aspecto positivo do toque e faz alusão à forma como o toque deve acontecer:

[...] o toque proporciona carinho e afeto, sendo muito importante saber como tocar, para ver como eles recebem, pegar mais suave quando é uma criança mais assustada ou se é uma criança mais agitada um toque um pouco mais firme, sempre se programando $e$ se policiando para passar essa mensagem para eles [...]. (A)

A família também deve se apropriar do toque na perspectiva terapêutica, visto que a criança não nasce afetiva, ela aprende o afeto por meio das manifestações familiares, conforme a percepção de um dos entrevistados:

[...] o toque deve ser utilizado pelos familiares para criação de vínculo, [...] realimentando o desejo de querer bem, trabalhando esse vínculo mãe-bebê [...]. (B)

A superação e a independência foram observadas e associadas ao toque:

[...] quando pegamos as crianças que todo mundo diz que são de difícil manejo e damos atenção, carinho e tocamos, conseguimos coisas que muitos dizem que não vamos conseguir, [...] são mínimas conquistas que assumem uma intensidade importantíssima para ela [...]. (C)

A questão da independência envolve o desenvolvimento da autonomia da criança especial, para que ela possa realizar atividades, tendo condições de cumprir tarefas do cotidiano inerentes à vida humana.

A segurança que o toque pode proporcionar também foi reforçada, conforme podemos observar na fala a seguir: 


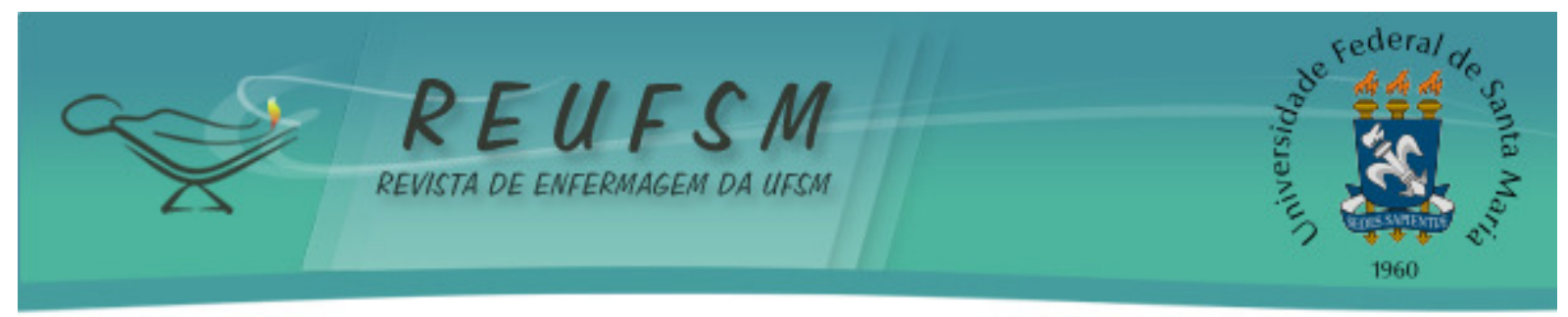

[...] o toque transmite segurança. Muitas crianças têm dificuldades de entender o que vai ser realizado e a fala às vezes não basta, então mostramos o que vai acontecer no atendimento $e$ isso ajuda bastante a criança tornando-a mais tranquila e segura [...]. (D)

A fala abaixo enfatiza a questão da imagem corporal, destacando não apenas a sua configuração estimulada pelo sensorial, mas o aspecto emocional tem grande envolvimento nesta questão:

O toque transmite confiança, respeito e retribuição de sentimentos, e é fundamental para configuração da imagem corporal e construção do sujeito e consciência de si mesmo. (A)

Percepções dos profissionais de saúde em relação à influência do toque: bem-estar da criança especial

No que diz respeito à condição de bem-estar, os entrevistados sentiram-se estimulados a tratar dos aspectos relacionados à humanização do cuidado e a valorização das crianças com necessidades especiais.

[...] através do toque as crianças se sentem valorizadas, sentem que não há preconceito, [...], porque às vezes essas crianças sofrem certo medo, as pessoas às vezes têm até medo de se aproximar, de tocar, de chegar; a forma do toque, a forma do carinho e do afeto com essas crianças faz com que elas se sintam também como todos nós e isso gera, para elas, conforto e alegria [...]. (E)

O toque transmite aconchego, proporciona proximidade, e permite a dasalienação, entretanto deve ser pactuado.

[...] o toque é uma via de contato com o mundo que muitas vezes eles têm cerceado pelas patologias e pelas limitações. Além disso, não é porque a criança está numa condição, às vezes, de alienação, [...], que iremos tocá-lo sem avisá-lo, [...] mesmo que ele esteja aparentemente alheio, o toque se torna uma via importantíssima de comunicação. (F)

0 toque foi relacionado como a proximidade, o estabelecimento de vínculo e com a aceitação da criança, pois quando a criança é tocada de forma carinhosa ela se sente aceita por quem a toca.

Percepções dos profissionais de saúde em relação à influência do toque: reabilitação da criança especial

A comunicação foi destacada como ferramenta chave para estabelecer um relacionamento com a criança especial:

[...] é necessário desenvolver toda uma linguagem com eles, que é muito corporal, como realizar um atendimento de um paciente que não usa a fala se eu não tiver outros recursos? Esses recursos, 


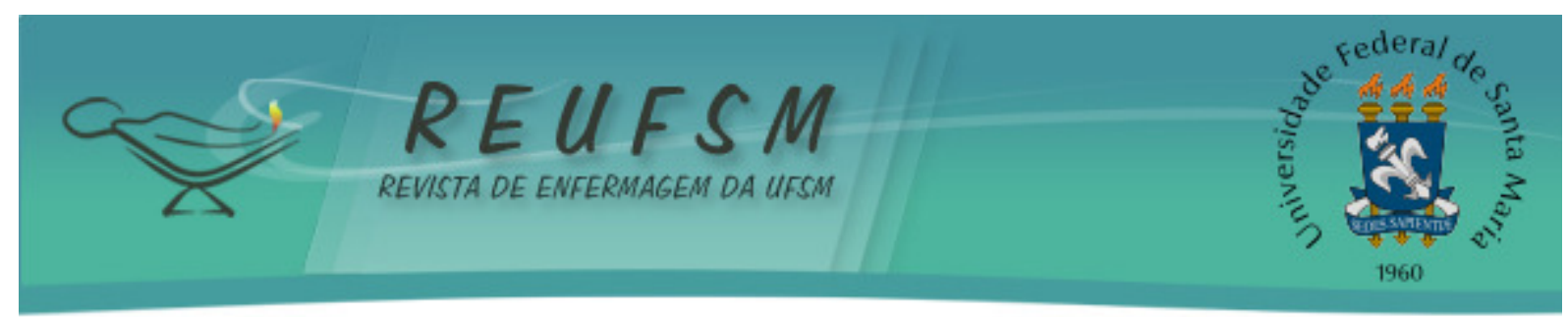

muitas vezes, passam assim pelo toque por trabalhar uma ficha de comunicação alternativa [...]. (B)

[...] o toque é fundamental para conhecer o paciente e criar um vínculo, para não invadir a criança, para que possa se entregar sem medo! Assim, tendo uma boa resposta da criança e uma boa reabilitação [...]. (E)

A interação é um elemento muito importante durante a reabilitação, pois se não ocorrer uma interação no olhar, no toque, sentindo a criança de outras formas, o atendimento se torna difícil, aspectos estes ilustrados também no relato a seguir:

[...] o toque proporciona a criação do vínculo terapeuta e paciente, pois permite uma melhora nos resultados, fazendo com que elas se esforcem mais para chegar aos objetivos que queremos e que precisam [...]. (C)

\section{DISCUSSÃO}

$\mathrm{Na}$ instância do desenvolvimento da criança especial, o toque é capaz de emitir mensagens positivas ou negativas, dependendo do momento, da forma e do local do corpo em que ocorre. ${ }^{6}$ Acrescenta-se que 0 ato físico em si não é um acontecimento emocional, mas seus elementos sensoriais provocam alterações neurais, glandulares, musculares e mentais, que chamamos emoções, por isso, muitas vezes, o tato não é sentido como uma sensação e sim, afetividade. ${ }^{12}$

0 toque é essencial para a criação do vínculo, pois permite um reconhecimento mútuo, já que a criança passa a sentir o cuidador e vice-versa. Na ampliação desta percepção o toque é um facilitador no desenvolvimento de afinidades, na medida em que as crianças podem expressar melhor o carinho por palavras e na reciprocidade do toque. Afinal, para estabelecer o cuidado podem ser organizadas estratégias e condutas para que o objetivo seja alcançado. ${ }^{7}$

Avançando neste debate, a rede de apoio familiar favorece a formação de vínculos e a estruturação da vida da criança com deficiência física, ampliando suas possibilidades a partir da autoestima advinda da afetividade. Esta rede possibilita o desenvolvimento e à socialização dessa criança. ${ }^{13}$

O desenvolvimento de uma criança com necessidades especiais está relacionado a diversos fatores: o cuidado recebido; a estimulação física e cognitiva. A família é essencial neste processo, a sua presença permite a superação de limites e possibilita a busca para melhores condições de vida. ${ }^{14}$

Logo, a segurança proporcionada pelo toque, quando realizado em qualquer época da vida, como um contato terno e amoroso na pele produz a sensação de apoio, consolo, companhia e presença amiga. Um contato rude e agressivo faz a pessoa sentir-se rejeitada, desprezada, invadida e provoca-lhe reação de defesa ou raiva. ${ }^{8}$ Por meio do toque existe retribuição de sentimentos, ratificando-se a confiança e o respeito.

Para que o cuidado seja possível, é necessário olhar para si e para o outro, na tentativa de que o autoconhecimento colabore no cuidado de cada ser. 0 encontro entre cuidador e o ser cuidado proporciona a criação de um elo empático que norteará as ações do cuidado. ${ }^{15} \mathrm{O}$ diálogo também é importante e mostra que o cuidado, ao ser estabelecido, deve ser considerado os saberes de cada um, uma vez que ambos são importantes. ${ }^{14}$

A criança com necessidade especiais se configura na família como um ser frágil que necessita de cuidados. ${ }^{3,14}$ A configuração da imagem corporal, construção do sujeito e consciência de si mesmo, foi enfocada neste estudo, pois as relações que envolvem o fator 


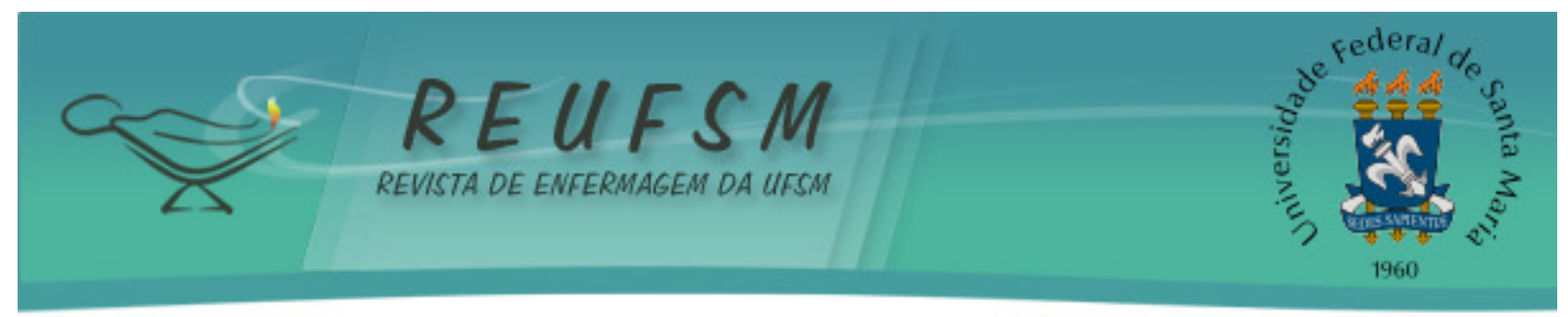

identidade relacionam-se com as definições elaboradas e adotadas no contexto social por pessoas que não possuem algum tipo de necessidade. ${ }^{16}$

0 reconhecimento da imagem de si reflete a autoconsciência e está associado com a idade mental em que se encontra a criança. ${ }^{17}$ Por fim, facultando-se a conquista da autonomia como fundamental no cuidado desenvolvido à criança com necessidades especiais, permite-se que ela atinja o seu maior nível possível de funcionamento físico, mental, espiritual e social. ${ }^{18}$

A busca pela autonomia é constante para a criança com necessidades especiais. 0 processo de reabilitação/habilitação promove e possibilita tal objetivo. Ser autônomo condiz com a possibilidade de escolha, de autogoverno, de decidir o que pode ser ideal para o cuidado e também conciliar com as atividades diárias, mas não necessariamente executá-las. ${ }^{19-20}$

Desta forma, o toque é um meio de comunicação utilizado pelos profissionais durante a realização de suas atividades. É por meio dele que se torna possível a troca de informações na assistência às crianças com necessidades especiais, sendo um dos meios pelos quais se faz o entendimento e se dá o retorno de suas necessidades. 0 toque, também, tem influência para o desenvolvimento psicossocial dessas crianças, pois é possível transmitir afeto, carinho, independência, superação de limitações e auxiliar na sua própria construção física e emocional. Por meio do toque pode-se transmitir segurança, proteção e atenção à pessoa a ser cuidada. ${ }^{21} \mathrm{Em}$ questão ao desenvolvimento destas crianças, outros instrumentos igualmente aceitáveis, são o olhar e o falar. Afinal, o cuidado humanizado é concretizado por meio do olhar atento e a empatia praticada pelos profissionais. ${ }^{22-23}$

No que tange a sensação de bem-estar que o toque possa proporcionar a criança especial, como uma necessidade de saúde em uma performance psicossocial, estudos comprovam um processo histórico de exclusão das crianças com necessidades especiais. Os mesmos reportam-se a não observância de seus direitos fundamentais e o tratamento como verdadeiros objetos, vitimadas pelas próprias deficiências e quando há inacessibilidade, surge a privação do direito de ir e vir que qualquer pessoa possui, proporcionando sua exclusão pela sociedade. ${ }^{3}$

Nesta perspectiva, o olhar cuidadoso à criança é fundamental para compreendê-la em sua integralidade, não focando apenas as características que the confere limitações ${ }^{1}$, e sim as considerando cidadãs com direitos que devem ser respeitados. Neste contexto, é preciso que se estabeleça um "olhar mais vigilante" que busque 0 atendimento a diversidade, em que se proponha uma maior atenção às diferenças, e que se estabeleça com a criatividade necessária. ${ }^{24}$

$\mathrm{Na}$ percepção dos profissionais entrevistados, o toque influencia no bem-estar de crianças especiais, pois por meio dele é possível aproximar e passar uma imagem de igualdade e aceitação, minimizando o medo e a rejeição que elas ainda sofrem em relação à sociedade. 0 toque transmite suporte emocional à pessoa a ser cuidada, proporciona calor humano que reflete em uma mensagem de conforto, afinal a pessoa a ser cuidada não está sozinha diante da dor e do sofrimento que a atinge. ${ }^{5,23}$

Com relação à reabilitação, esta contempla múltiplas dimensões, se compreendida como um processo que vai além da recuperação de funções perdidas ou alteradas. Vale ressaltar que o processo de reabilitação de crianças com necessidades especiais, por vezes, pode ser considerado como habilitação, pelo fato da criança não possuir outra experiência diferente da vivenciada atualmente. Trata-se de uma especialidade, na área da saúde, a qual aborda o indivíduo em constante interação. O processo de reabilitação/habilitação é longo e envolve componentes psicossociais, espirituais, econômicos e políticos, sendo muitas vezes um desafio tanto para a pessoa como para a equipe. Ele é, essencialmente, dinâmico multi e interdisciplinar, fazendo interface com várias ciências. ${ }^{25}$

Independente de sua área de formação básica, seja ela enfermagem, fisioterapia, medicina, psicologia, entre outras, estes profissionais têm como base de seu trabalho as relações humanas. ${ }^{12} 0$ cuidado só se torna efetivo quando a interação entre os profissionais acontece e permite o estabelecimento de melhores condições a pessoa que é 


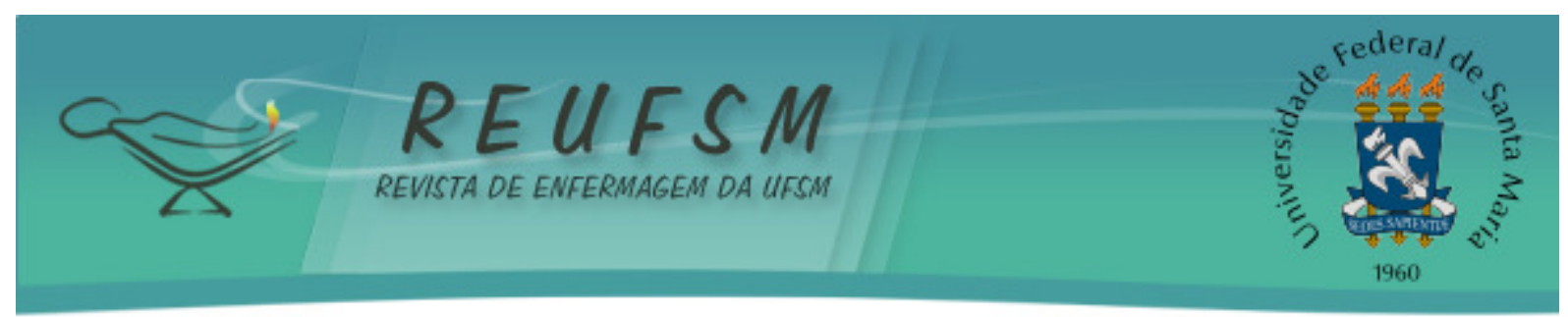

cuidada. A assistência interdisciplinar é relevante na reabilitação/habilitação da criança com necessidades especiais. Assim, cada profissional da saúde membro da equipe interdisciplinar possui um papel importante na assistência prestada. Afinal, quando há comunicação efetiva dos profissionais com as pessoas a serem cuidadas todo o cuidado promovido resulta em uma assistência de qualidade. ${ }^{26}$

E, para permitir ser cuidado, a pessoa precisa sentir-se segura, confiar no profissional. Esse vínculo de confiança é dependente da comunicação interpessoal, uma vez que só é possível confiar em alguém quando percebe-se coerência e constância entre o que ele diz e o que ele faz. ${ }^{12}$

A luz destas idéias reforça-se a temática da interação reportando que o toque não deve tratar somente a situação física e motora, mas, principalmente a questão sentimental, pois com o toque é possível proporcionar carinho, criando um vínculo de amizade e afeto.

Ainda, o toque pode ser visto como a primeira porta de entrada, sendo uma forma de apresentação para a criança. Ele comunica quem está chegando, estabelece ou não, um processo de colaboração entre a criança e o cuidador. Agregou-se no cenário em estudo a ideia de que o toque na reabilitação auxilia na evolução, pois as crianças se sentem mais seguras, aliviando seus temores e ansiedades.

Demonstrações de carinho por meio do toque, quando utilizados pelos profissionais, aliviam o sofrimento das crianças, reduzindo suas ansiedades. Possibilitando uma interação efetiva e fundamental para o desenvolvimento do cuidado individualizado ${ }^{8}$, efetivando com isso o processo de reabilitação/habilitação.

\section{CONSIDERAÇÕES FINAIS}

O toque é uma ferramenta importante de comunicação entre o profissional e a criança sendo fundamental para a criação do vínculo e desenvolvimento da criança. Além disso, o toque como instrumento de cuidado, disponibiliza a troca de afetividade entre a criança e o cuidador, possibilitando segurança e igualdade. Em relação à reabilitação, ele promove conforto melhorando o atendimento, trazendo resultados esperados e satisfatórios.

Permeando a criança com necessidades especiais há um ser sensível que merece carinho e atenção. Mesmo que sua capacidade de expressão esteja limitada na forma de demostrar seus desejos e necessidades, não significa que a capacidade de sentir esteja prejudicada. Logo, o toque assume uma via de comunicação não verbal e sensitiva, possível de ser entendida e estimulada por essas crianças.

0 amor incondicional é o sentimento básico que deve estar presente em toda equipe de reabilitação ligada aos cuidados das crianças especiais. A sensibilidade destes cuidadores é importante, para que possam compreender e atender as necessidades das crianças especiais, tendo em vista que a comunicação não é explícita e se faz necessária uma tradução por meio de uma linguagem sensitiva e interpretativa da linguagem corporal e das emoções que não são claras.

Os profissionais desta área não devem deter-se nas limitações e diferenças das crianças especiais, e sim identificar o potencial delas, possibilitando a melhora na qualidade de vida, sendo esta a chave do processo de liberdade no desenvolvimento das mesmas. Tal liberdade de expressão possibilita a autonomia, favorecendo o fluxo das necessidades específicas destas crianças, sejam elas, básicas ou complexas.

A ausência de estimulação sugestiona ao indivíduo a incapacidade, ou seja, a falta de entrega no seu processo de amadurecimento físico, mental e emocional, servindo como modelo deficiente na interação entre o cuidado e o cuidador. É justamente nos casos em que há escassez motora ou emocional que se torna necessária uma maior estimulação.

Entende-se, então, que o profissional necessita se identificar com este perfil, o qual exige perseverança e paciência; caso contrário, desencadeia um fator limitador das 


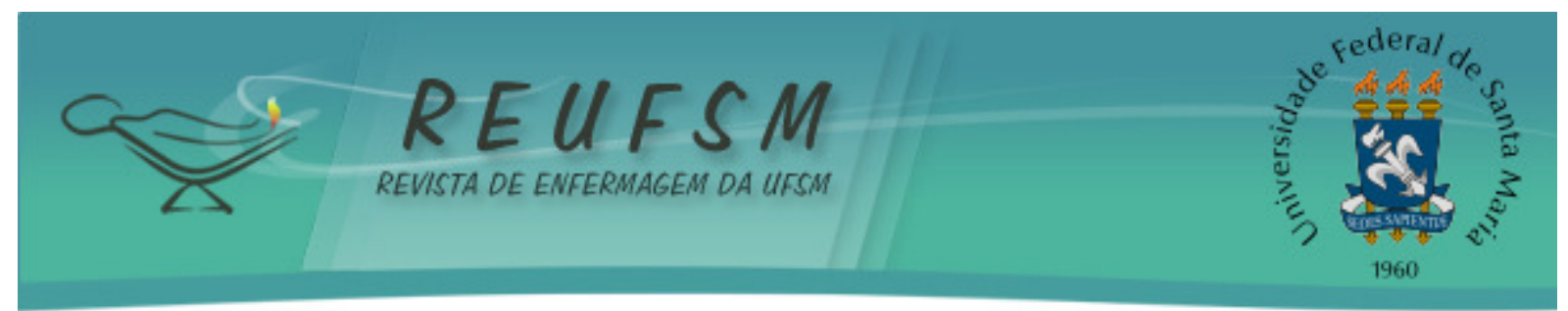

respostas do desenvolvimento de profissionais capacitados ao cuidado às crianças com necessidades especiais.

Os achados deste estudo evidenciam o quanto os profissionais percebem o toque como um modo distinto e especial no processo de cuidados. Deve-se, então, repensar questões referentes ao uso de ferramentas alternativas no cuidado às crianças especiais, já que na prática essas ferramentas trazem benefícios e melhoram a qualidade dos serviços prestados pela equipe.

Ressalta-se, assim, a importância da realização de novas pesquisas nessa área, a fim de conhecer melhor as estratégias a serem utilizadas nos cuidados das crianças com necessidades especiais, possibilitando novas vertentes de discussões acerca da profissionalização dessa atividade e, consequentemente, qualificar o cuidado.

\section{REFERÊNCIAS}

1. Brasil. Decreto Lei $n^{\circ} 3.298,20$ de dezembro de 1999. Regulamenta a Lei $n^{\circ} 7.853$, de 24 outurbo de 1989, dispõe sobre a Política Nacional para a Integração da Pessoa Portadora de Deficiência [Internet]. 1999 [acesso 2013 jun 23]. Disponível em: http://portal.mec.gov.br/seesp/arquivos/pdf/dec3298.pdf.

2. Instituto Brasileiro de Geografia e Estatística. Censo 2010. Censo demográfico: resultados preliminares da amostra [Internet]. 2013. [acesso 2013 out 27]. Disponível em: http://www.ibge.gov.br/home/estatistica/populacao/censo2010/resultados_preliminares_ amostra/default_resultados_preliminares_amostra.shtm.

3. Milbrath VM, Siqueira HCH, Amestoy SC, Cestari ME. Criança portadora de necessidades especiais: contrapontos entre a legislação e a realidade. Rev Gaúch Enferm [Internet]. 2009 [acesso 2013 jun 28];30(1):127-30. Disponível em: http://seer.ufrgs.br/RevistaGauchadeEnfermagem/article/view/3474/6570.

4. Sousa LFL, Leal AL, Sena EFC. A importância da comunicação não-verbal do professor universitário no exercício de sua atividade profissional. Rev CEFAC [Internet]. 2010 [acesso 2013 jun 23];12(5):784-7. Disponível em: http://www.scielo.br/pdf/rcefac/v12n5/13709.pdf.

5. Davis PK. O poder do toque. São Paulo: Best Seller; 1991.

6. Perencin CC, Ribeiro CA. Tocando o prematuro: significado para auxiliares e técnicas de enfermagem. Rev Bras Enferm [Internet]. 2011 [acesso 2013 jun 28]; 64(5):817-23. Disponível em: http://www.scielo.br/pdf/reben/v64n5/a03v64n5.pdf.

7. Organização Mundial da Saúde. Relatório mundial sobre a deficiência [Internet]. São Paulo: SEDPCD; 2012 [acesso 2013 jun 28]. Disponível em: http://whqlibdoc.who.int/publications/2011/9788564047020_por.pdf.

8. Dias $A B$, Oliveira $L$, Dias $D G$, Santana MG. $O$ toque afetivo na visão do enfermeiro. Rev Bras Enferm [Internet]. 2008 [acesso 2013 jun 23];61(5):603-7. Disponível em: http://www.scielo.br/pdf/reben/v61n5/a12v61n5.pdf.

9. Roxo JRS. O toque na prática clínica. Rev Referência [Internet]. 2008 [acesso 2013 jun 28];2(6):77-89. Disponível em: http://www.index-f.com/referencia/2008pdf/067789.pdf.

10. Brandão ESB, Bastos MRCM, Vila VSC. O significado da cirurgia cardíaca e do toque na perspectiva de pacientes internados em UTI. Rev Eletrônica Enferm [Internet]. 2005 [acesso 2013 jun 28];7(3):278-84. Disponível em: http://www.fen.ufg.br/revista/revista7_3/original_04.htm. 


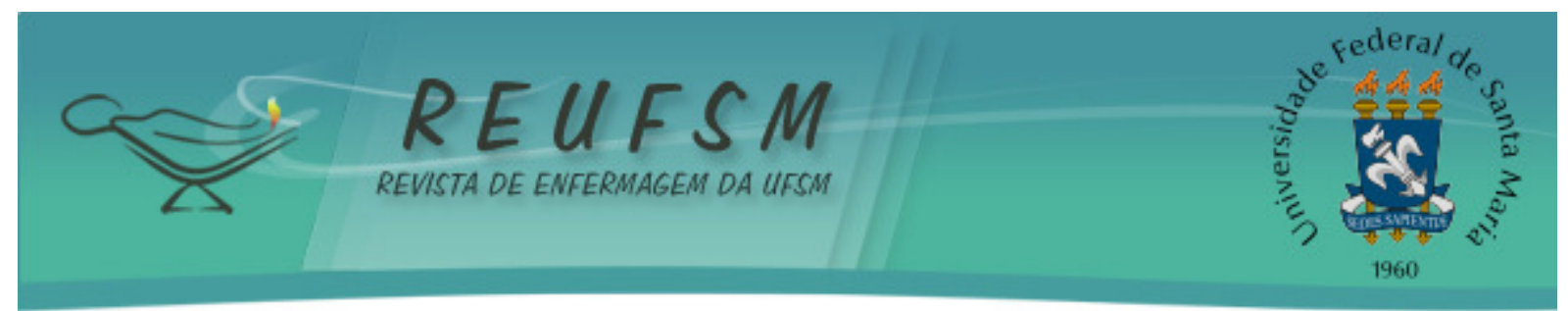

11. Minayo MCS. O desafio do conhecimento: pesquisa qualitativa em saúde. São Paulo: Hucitec; 2007.

12. Dias SMZ, Motta MGC. Práticas e saberes do cuidado de enfermagem à criança hospitalizada. Ciência Cuid Saúde [Internet]. 2004 [acesso 2013 maio 27];3(1):41-54. Disponível em: http://periodicos.uem.br/ojs/index.php/CiencCuidSaude/article/ view/5515/3507.

13. Sá SMP, Rabinovich EP. Compreendendo a família da criança com deficiência física. Rev Bras Crescimento Desenvolv Hum [Internet]. 2006 [acesso em 2013 maio 22];16(1):68-84. Disponível em: ttp://pepsic.bvsalud.org/pdf/rbcdh/v16n1/08.pdf.

14. Milbrath VM, Siqueira HCH, Motta MGC, Amestoy SC. Família da criança com paralisia cerebral: percepção sobre as orientações da equipe de saúde. Texto \& Contexto Enferm [Internet]. 2012 [acesso em 2013 jun 30];21(4):921-28. Disponível em: http://www.scielo.br/pdf/tce/v21n4/24.pdf.

15. Carvalho ARS, Pinto MCV, Matsuda LM, Scochi MJ. Cuidado e humanização na enfermagem: reflexão necessária [Internet]. In: Anais do $2^{\circ}$ Seminário Nacional Estado e Políticas Sociais no Brasil; 2005 out 13-15; Cascavel. Cascavel: Unioeste; 2005 [acesso em 2013 jun 27]. Disponível em: php.unioeste.br/projetos/gpps/midia/seminario2/trabalhos/saude/msau16.pdf.

16. Magalhães RCBP, Cardoso APLB. A pessoa com deficiência e a crise das identidades na contemporaneidade. Cad Pesqui [Internet]. 2010 [acesso em 2013 jun 27];40(139):45-61. Disponível em: http://www.scielo.br/pdf/cp/v40n139/v40n139a03.pdf.

17. Di Napoli FO, Bosa CA. As relações entre a qualidade da interação mãe-criança e o reconhecimento da imagem em si em crianças com autismo. Rev Bras Cres Desenv Hum. 2005;15(3):11-25.

18. Moreira ELM, Moreira LFR, Donoso MTV. A questão do portador de necessidades especiais: uma reflexão. REME Rev Min Enferm [Internet]. 2007 [acesso em 2013 maio 23];11(4):461-4. Disponível em: http://www.revenf.bvs.br/pdf/reme/v11n4/v11n4a18.pdf.

19. Borges AMF, Brignol P, Schoeller SD, Bonetti A. Percepção das pessoas com lesão medular sobre a sua condição. Rev Gaúch Enferm [Internet]. 2012 [acesso em 2013 jun 15];33(3):119-25. Disponível em: http://www.scielo.br/pdf/rgenf/v33n3/16.pdf.

20. Zem-Mascarenhas SH, Barros ACT. O cuidado no domicílio: a visão da pessoa dependente e do cuidador. Rev Eletrônica Enferm [Internet]. 2009 [acesso em 2013 jun 25];11(1):45-54. Disponível em: http://www.fen.ufg.br/fen_revista/v11/n1/pdf/v11n1a06.pdf.

21. Porfírio $A B$, Progianti JM, Souza DO. As práticas humanizadas desenvolvidas por enfermeiras obstétricas na assistência ao parto hospitalar. Rev Eletrônica Enferm [Internet]. 2010 [acesso em 2013 jun 25];12(2):331-6. Disponível em: http: //www.fen.ufg.br/revista/v12/n2/pdf/v12n2a16.pdf.

22. Barlem ELD, Rosenhein DPN, Lunardi VL, Lunardi Filho WD. Comunicação como instrumento de humanização do cuidado de enfermagem: experiências em unidade de terapia intensiva. Rev Eletrônica Enferm [Internet]. 2008 [acesso 2013 jun 25]; 10(4):10419. Disponível em: http://www.fen.ufg.br/revista/v10/n4/pdf/v10n4a16.pdf.

23. Araujo MMT, Silva MJP. Estratégias de comunicação utilizadas por profissionais de saúde na atenção à pacientes sob cuidados paliativos. Rev Esc Enferm USP [Internet]. 2012 


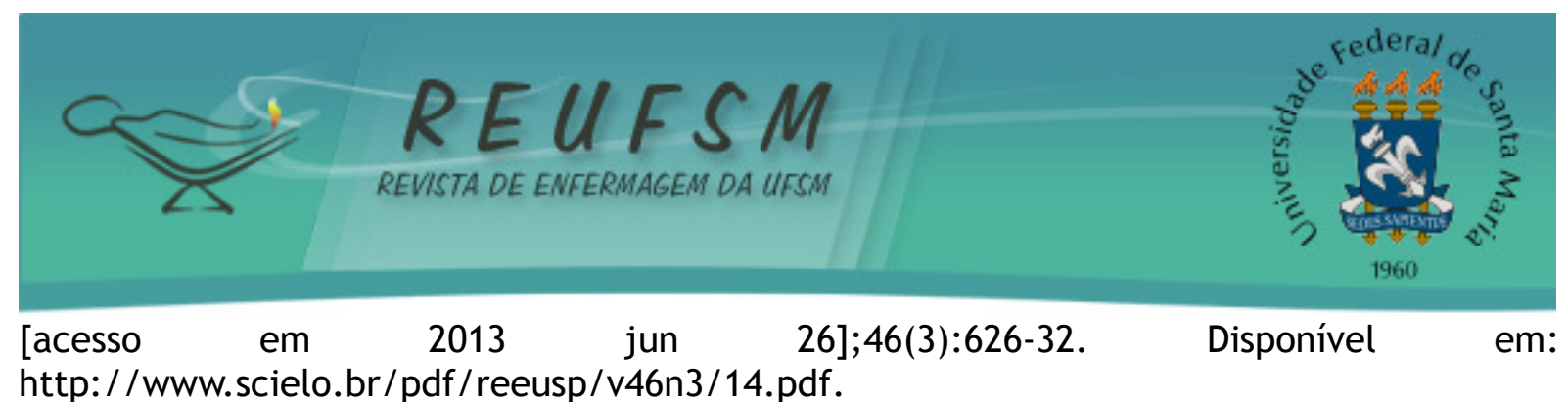

24. Braga AF. Educação inclusiva: das intenções às ações - um estudo sobre o processo de inclusão escolar de alunos caracterizados como portadores de necessidades especiais em escolas públicas no município de Viçosa, MG [dissertação]. Viçosa: Universidade Federal de Viçosa; 2006.

25. Faro ACM. Enfermagem em reabilitação: ampliando os horizontes, legitimando o saber. Rev Esc Enferm USP [Internet]. 2006 [acesso em 2013 jun 28];40(1):128-33. Disponível em: http://www.scielo.br/pdf/reeusp/v40n1/a18v40n1.pdf.

26. Vargas JS, Rezende MS. Comunicação: equipe de enfermagem e paciente em ventilação mecânica. Rev Enferm UFSM [Internet]. 2011 [acesso em 2013 ago 20]; 1(3):412-9. Disponível em: http://cascavel.ufsm.br/revistas/ojs2.2.2/index.php/reufsm/article/view/3380/2391.

Data de recebimento: 19/07/2013

Data de aceite: $14 / 11 / 2013$

Contato com autor responsável: Julia Vargas de Oliveira Vargas Bitencourt

Endereço: Rua das Hortências, $\mathrm{n}^{\circ}$ 221, Bairro DiFiori, Guatambu - Santa Catarina, CEP: 89.817-000

E-mail: ivanorbitencourt@gmail.com 